\title{
Microstructure Characterization of ZK60 Magnesium Alloys Using TEM and HR-EBSD
}

\author{
Jae-Hyung Cho, ${ }^{1, *}$ Soo-Hyun Kim, ${ }^{2}$ Sang-Ho Han, ${ }^{1}$ and Suk-Bong Kang ${ }^{1}$ \\ ${ }^{1}$ Korea Institute of Materials Science, 797 Changwondaero, Seongsan-gu, Changwon, Gyeongnam 641-831, Republic of Korea \\ ${ }^{2}$ Busan Techno Park, 1274 Jisa-dong, Gangseo-gu, Busan 618-230, Republic of Korea
}

\begin{abstract}
ZK60 (Mg-Zn-Zr) alloys exhibited a variation in precipitates with aging, and their mechanical properties also changed. Microindentation tests were carried out on two types of ZK60 alloys of solid solution (T4) and peak aging (T6). Microstructure and texture evolution during indentation was investigated using electron backscatter diffraction. Twinning occurred near the indentation marks in most grains. It was found that tensile twinning was dominant, and two twin variants were usually observed. Texture and microstructure evolution by twinning and slip activation was further examined by uniaxial compression test with strain. The initial random orientation gradually changed into basal fibers with strain. Some grains with nonbasal orientations aligned with the loading direction easily underwent twinning followed by slip deformation. Other grains near basal orientations revealed only slip deformation.
\end{abstract}

Key words: magnesium alloys, ZK60, indentation, compression, microstructure, EBSD, TEM, twin variants

\section{INTRODUCTION}

Magnesium alloys have recently drawn large attention from the parts manufacturing industries for automobile, aerospace, and electronics because of their light weight and high specific strength. Particularly, wrought magnesium alloys of ZK60 (Mg-Zn-Zr) possess both high strength and elongation (Cho et al., 2007; Chen et al., 2009) and exhibit great potential in industrial applications. Mg-Zn system has been known for its precipitate hardening behaviors, and an addition of $\mathrm{Zr}$ elements to the $\mathrm{Mg}-\mathrm{Zn}$ system refined its grain size and improved its mechanical properties. Thus, ZK60 revealed the aging behaviors of $\mathrm{Mg}-\mathrm{Zn}$ and better mechanical properties owing to the fine-grained structure formed by the addition of $\mathrm{Zr}$ (Wei et al., 1995a, 1995b; He et al., 2006; Xu et al., 2006; Gao \& Nie, 2007).

During isothermal aging of the $\mathrm{Mg}-\mathrm{Zn}$ system, an evolution of precipitates was found to occur in addition to bulky shaped particles being formed at the casting stage. It is known that variations in $\mathrm{Zn}$ contents, from 3 to $6 \%$ in weight, affect the age hardening responses (Maeng et al., 2000). As Zn contents increased, more precipitates were formed. After overaging, the microhardness gradually decreased. Change in precipitate with aging also affects the mechanical properties of ZK60.

Rolled Mg alloys usually have a strong basal intensity because of easy activation of basal slip systems. Nonbasal slip systems have much higher critical resolved shear stresses than basal slip systems at room temperature, and it is difficult for a nonbasal system to get activated. Limited slip systems also result in twinning activation to accommodate plastic deformation. Various researches have been conducted to better understand the plastic deformation and

() MICROSCOPY SOCIETY OF AMERICA 2013

${ }^{\star}$ Corresponding author. E-mail: jhcho@kims.re.kr texture evolution of hexagonal materials (Agnew et al., 2001; Agnew \& Duygulu, 2005; Choi et al., 2007).

In this paper, the variation in texture and microstructure that occurs during the deformation of ZK60 alloys was investigated. Two types of ZK60 specimens were prepared: one by solid solution heat treatment (T4) and the other by solid solution heat treatment followed by artificial aging (T6). The samples obtained by artificial aging showed hardness peaks due to precipitates. Various precipitates were observed by transmission electron microscopy (TEM). Microindentation and uniaxial compression tests were carried out at room temperature and at elevated temperatures, respectively. Closer observations of evolution of microstructure and texture were made using electron backscatter diffraction (EBSD). The EBSD system was effectively used for examination of deformation and recrystallization of magnesium alloys (Lorimer \& Mackenzie, 2005).

\section{Materials and Methods}

The ZK60 magnesium alloys used in this study had a chemical composition of $5.47 \mathrm{Zn}-0.58 \mathrm{Zr}-\mathrm{Mg}$ (in wt $\%$ ). The detailed chemical composition is listed in Table 1. The alloys were originally fabricated by ingot casting (IC), and then they were solution heat-treated at $673 \mathrm{~K}$ for $15 \mathrm{~h} \mathrm{(T4);} \mathrm{this}$ was followed by artificial aging (T6) at $448 \mathrm{~K}$ for $12 \mathrm{~h}$.

Heat treatments and the associated mechanical properties for the solid solution and aging hardening of ZK60 alloys were studied in previous works (Cho et al., 2007; Chen et al., 2009). The ZK60 alloys show hardness variations during aging. The hardness value after solid solution was $\sim 66 \mathrm{HV}$. It increased to a maximum of $74 \mathrm{HV}$ after $12 \mathrm{~h}$. The hardness value dropped after $100 \mathrm{~h}$ because of overaging.

Microindentation tests at room temperature were performed using a load of 50 or $100 \mathrm{gf}$. The surface of the 
Table 1. Chemical Composition of ZK60 Alloys.

\begin{tabular}{lcccccccccc}
\hline Alloying Element & $\mathrm{Al}$ & $\mathrm{Zn}$ & $\mathrm{Mn}$ & $\mathrm{Si}$ & $\mathrm{Fe}$ & $\mathrm{Cu}$ & $\mathrm{Ni}$ & $\mathrm{Ca}$ & $\mathrm{Zr}$ & $\mathrm{Mg}$ \\
\hline $\mathrm{wt} \%$ & 0.01 & 5.47 & 0.009 & 0.022 & 0.003 & 0.003 & 0.007 & 0.005 & 0.58 & Bal.
\end{tabular}

ZK60 sample was cleaned to obtain a clear indentation size. Mechanical polishing followed by electropolishing was carried out for EBSD sample preparation. Some specific grains were measured using EBSD to capture the microstructure evolution during indentation. The grain size of the ZK60 samples was $\sim 200 \mu \mathrm{m}$. The indentation size was mostly $<50 \mu \mathrm{m}$, and it was ensured that the marks be located inside grains of interest. A load of $<50$ gf was ineffective for capturing the twinning activation.

Uniaxial compression tests were carried out using Thermecmastor-Z (Fuji Electronic Industrial Co.). The cylindrical compression samples were $12 \mathrm{~mm}$ in length and $8 \mathrm{~mm}$ in diameter. The deformation temperature for the compression was $523 \mathrm{~K}$, and the strain rate was $0.32 / \mathrm{s}$.

Microstructure and microtexture analyses were performed using an automated HR-EBSD (JEOL7001F) with HKL Channel5 and a generalized EBSD data analysis code, namely, REDS (Cho et al., 2005). EBSD samples were mechanically polished, and then electropolished using a solution of butyl cellosolve $(50 \mathrm{~mL})$, ethanol $(10 \mathrm{~mL})$, and perchloric acid $(5 \mathrm{~mL})$ at a voltage of $10 \mathrm{~V}$ and a temperature of $253-258 \mathrm{~K}$. More detailed examinations of microstructure and precipitates were made using a JEM-2100F TEM operating at $200 \mathrm{kV}$. TEM samples were prepared by a dual focused ion beam (FIB, TESCAN LYRA).

\section{Results AND Discussion}

Figure 1 shows TEM micrographs that reveal change in the distribution of precipitates with aging. The aging particles mainly contributed to an increase in hardness. Aging heat treatment, however, little affects the overall grain morphology and texture.

Optical micrographs (OM) and inverse pole figure (IPF) maps near microindented regions are shown in Figure 2. In the IPF maps, the normal direction is parallel with the loading direction (LD). Figures $2 \mathrm{a}$ and $2 \mathrm{~d}$ are initial images before indentation for the solid solution samples, and Figure $2 \mathrm{~g}$, for the aged samples, respectively. Figures $2 \mathrm{a}$ and $2 \mathrm{~b}$ show the optical micrographs taken before and after the indentation (50 gf) of the grain orientation, Euler angles, $\left\{174.4^{\circ}, 127.1^{\circ}, 43.0^{\circ}\right\}$, and Figure $2 c$ illustrates the IPF map near the indentation mark. The arrow indicates the same direction in the OM and IPF maps. Twinned regions near the indentation mark were observed, in addition to slip deformation. The slip deformation due to indentation caused intra-misorientation inside the grains. All the twins in the micrographs were found to be tensile twins (TTW). There were two twin variants, namely, TTW $1,\left\{95.5^{\circ}, 79.7^{\circ}, 23.8^{\circ}\right\}$, and TTW2, $\left\{54.1^{\circ}, 121.6^{\circ}, 13.4^{\circ}\right\}$, inside the grains (Fig. 2c). One side of the diamond mark contained both the TTW1 and TTW2 regions. All of them had the TTW relationships of a misorientation angle and axis of $\sim 86^{\circ}\langle 11 \overline{2} 0\rangle$ with the untwined region.

Figures $2 \mathrm{~d}-2 \mathrm{f}$ show the micrographs taken before and after the indentation of two adjacent grains (solid solution sample). The left grain is located on the left side of the indentation, and its orientation is $\left\{31.8^{\circ}, 26.1^{\circ}, 21.5^{\circ}\right\}$. The orientation of the right grain is $\left\{50.9^{\circ}, 24.3^{\circ}, 34.2^{\circ}\right\}$, and the overall misorientation angle of the two adjacent grains is $28^{\circ}$. Each grain has two twin variants: $\left\{143.6^{\circ}, 80.9^{\circ}, 53.5^{\circ}\right\}$ and $\left\{88.5^{\circ}, 102.3^{\circ}, 51.9^{\circ}\right\}$, for the left grain, and $\left\{176.3^{\circ}\right.$, $\left.75.2^{\circ}, 48.9^{\circ}\right\}$ and $\left\{120.1^{\circ}, 99.4^{\circ}, 51.3^{\circ}\right\}$, for the right grain. On the right grain, TTW1 touches the corner of the diamond mark and TTW2 starts from the side of the mark. Apparently, TTW1, on the right grain, was blocked by other grains located above the right grain. On the left grain, the zigzag-shaped TTW2 region had the same orientation, and it was separated from TTW1.

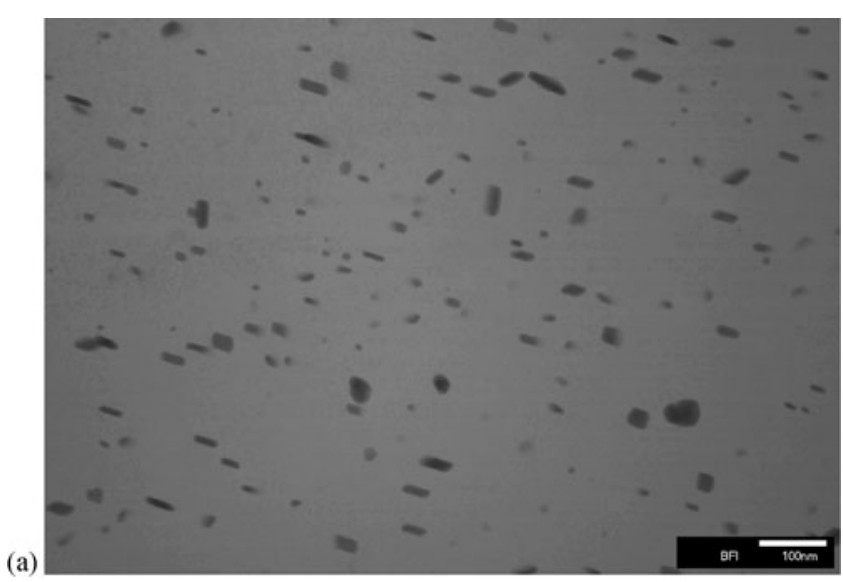

(a)

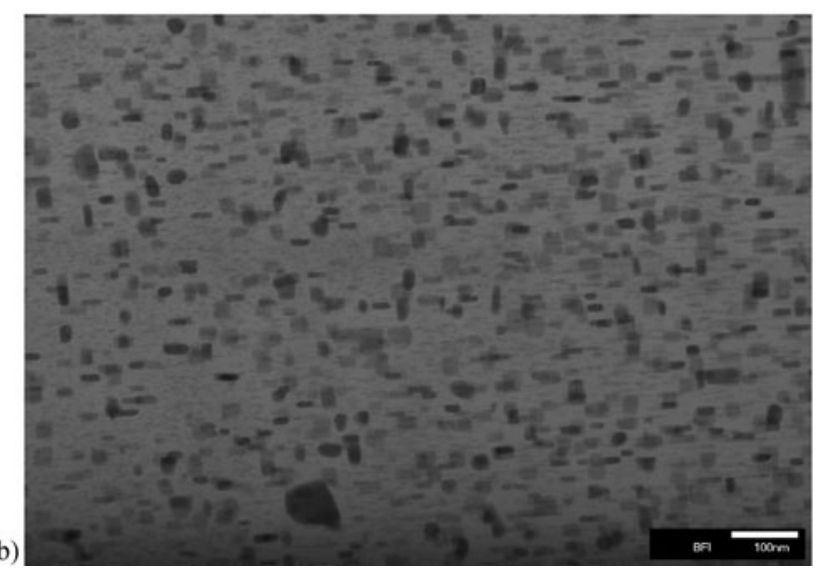

Figure 1. Transmission electron microscopy micrographs showing distribution of precipitates: (a) solid solution and (b) peakaged samples. 
(a)

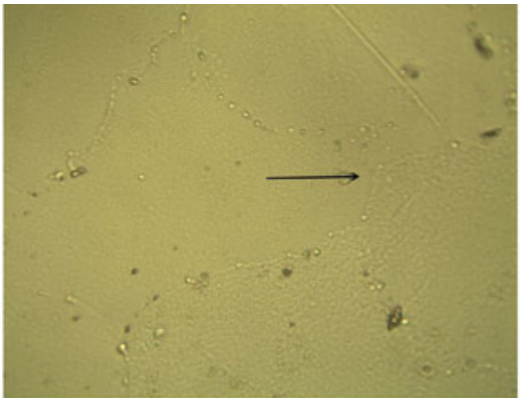

(b)

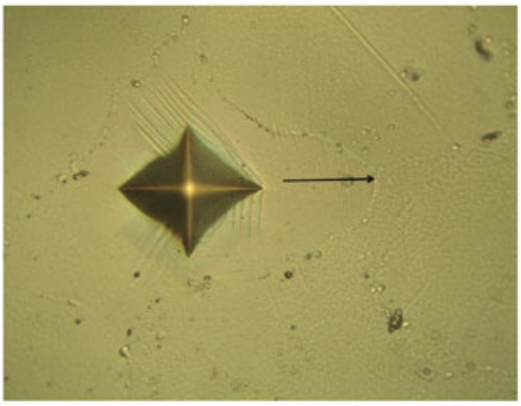

(c)

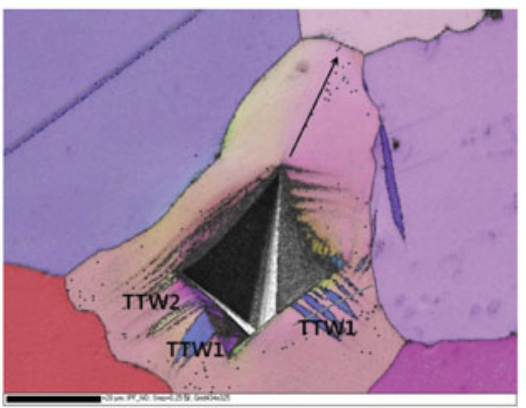

(d)
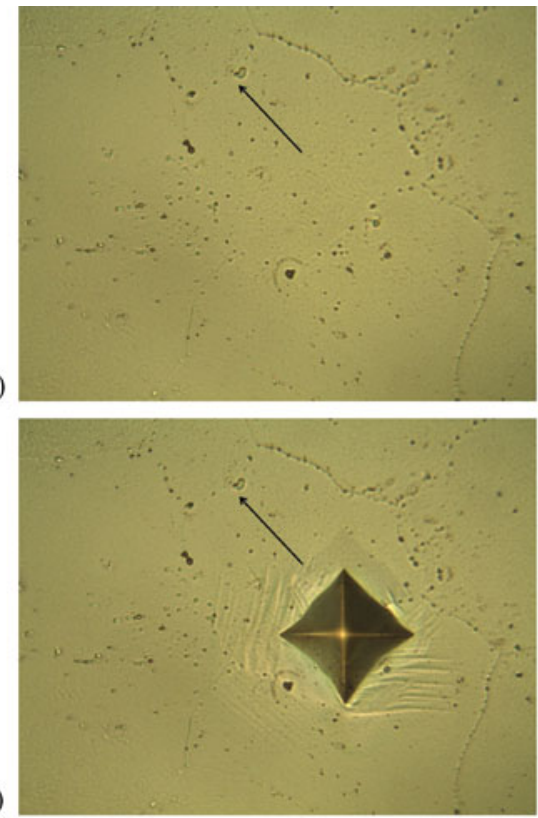

e)

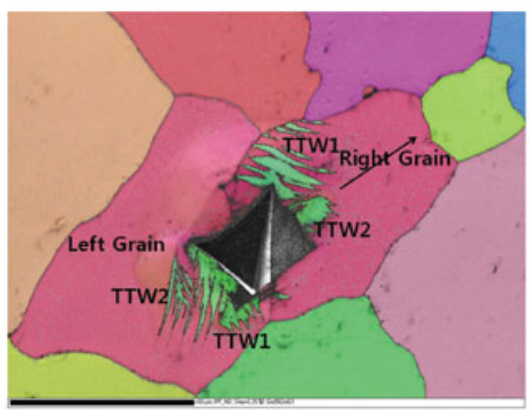

(g)

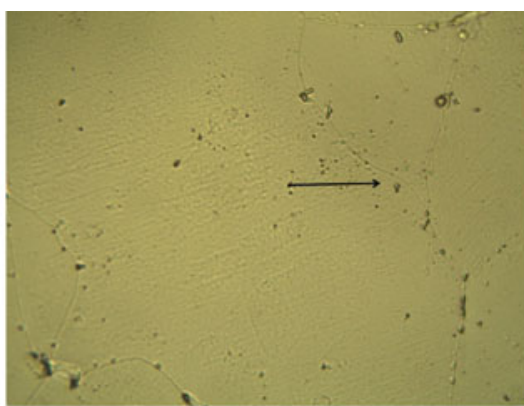

(h)

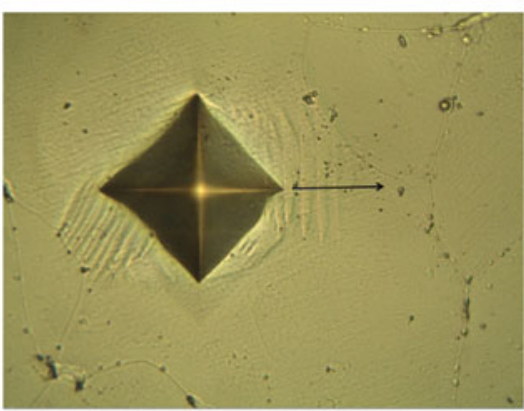

(i)

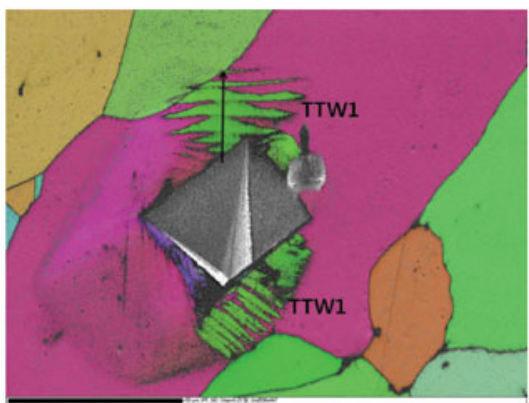

Figure 2. Optical micrographs and inverse pole figure maps near a microindentation: $(\mathbf{a}-\mathbf{c})$ are for the orientation $\left\{174.4^{\circ}, 127.1^{\circ}, 43.0^{\circ}\right\}$; (d-f) are for the two orientations $\left\{50.9^{\circ}, 24.3^{\circ}, 34.2^{\circ}\right\}$ and $\left\{31.8^{\circ}, 26.1^{\circ}, 21.5^{\circ}\right\}$; and $(\mathrm{g}-\mathbf{i})$ are for the orientation $\left\{92.9^{\circ}, 34.8^{\circ}, 25.1^{\circ}\right\}$. The indentation load for (b) and (e) was 50 gf (solid solution samples) and that for (h) was $100 \mathrm{gf}$ (aged samples).

Figures $2 \mathrm{~g}-2 \mathrm{i}$ show the micrographs taken before and after the indentation for the grain, $\left\{92.9^{\circ}, 34.8^{\circ}, 25.1^{\circ}\right\}$. Only one twin variant, $\left\{20.5^{\circ}, 106.1^{\circ}, 58.9^{\circ}\right\}$, was observed. Twins blocked by adjacent grains were also observed near the top area of the mark. From these indentation results, it was found that the overall misorientation angle and axis between the parent matrix and tensile twinning were $\sim 86^{\circ}\langle 11 \overline{2} 0\rangle$.

TTW variants observed in the twinned grains showed three different types of misorientation angle/axis: $7.4^{\circ}\langle 1 \overline{2} 10\rangle$, $60^{\circ}\langle 10 \overline{1} 0\rangle$, and $60.4^{\circ}\langle 8 \overline{1} 70\rangle$ as reported by Nave and Barnett (2004). Three complete pole figures, (0002), (1120), and (1010), showing the typical positions of the matrix and two TTW variants shown in Figure $2 \mathrm{c}$ are presented in Figure 3. The two twin variants have the relation of $\sim 60^{\circ}$ $\langle 10 \overline{1} 0\rangle$, which shows the twinning type of $(10 \overline{1} 2)-(01 \overline{1} 2)$. During indentation, the grain boundaries of indented grains frequently moved outward. This resulted in a deformation in the adjacent grains. Some of the adjacent grains exhibited tensile twinning, whereas the others just accommodated the plastic deformation via slip without exhibiting twinning.

Twinning activation and texturing at the beginning of plastic strain was further examined using two different samples, i.e., solid solution (T4) and aged (T6) samples. Figure 4 displays IPF maps at a strain of $2.5 \%$ for both the solid solution (T4) and the aged (T6) ZK60 alloys. The original samples used were made by IC, and the initial texture was similar to a random distribution, which was typical for the usual casting structure. With an increase in strain, the basal peak intensity continued to increase. The difference in the misorientation angle distribution between the two samples was not evident in the EBSD mapping results. Some grains revealed the initial stage of twinning, and a sharp- and narrow-shaped twin region was observed in the parent matrix. Other grains contained wide twinned region, which implies twinning propagation into the parent matrix in progress. Most of the twinned regions have one twin variant, and a few grains had two twin variants. The other grains just exhibited slip deformation without twinning. Similar to the indentation experiments, most of the twins were tensile twinning, i.e., $86^{\circ}\langle 11 \overline{2} 0\rangle$, and two twin variants in the same matrix had the relationship of mainly $60^{\circ}\langle 10 \overline{1} 0\rangle$. The highest frequency of a misorientation angle of $\sim 86^{\circ}$ is associated with tensile twinning activation for both the solid solution and the aged ZK60 alloys. 
(a)
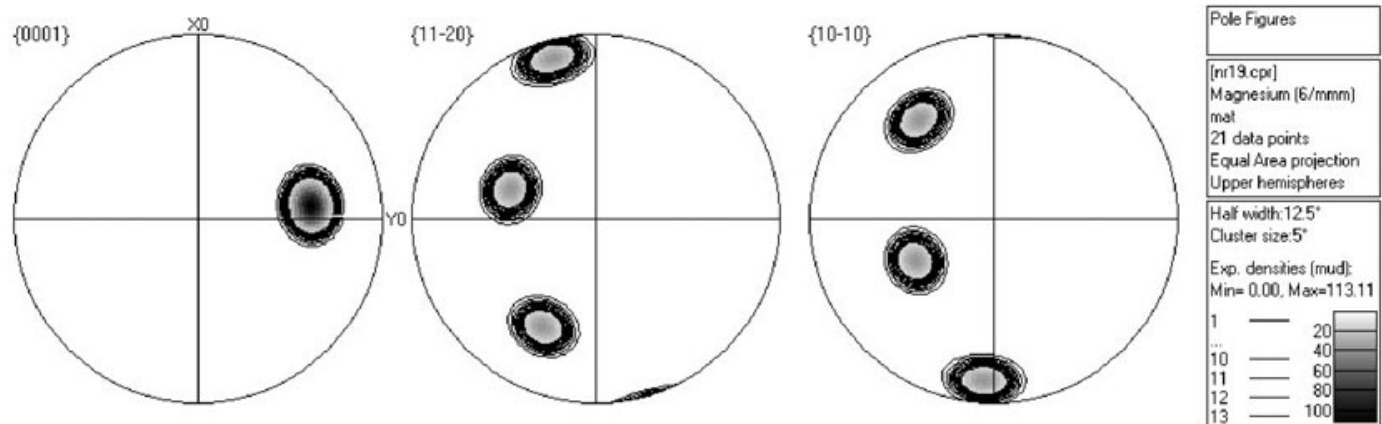

(b)
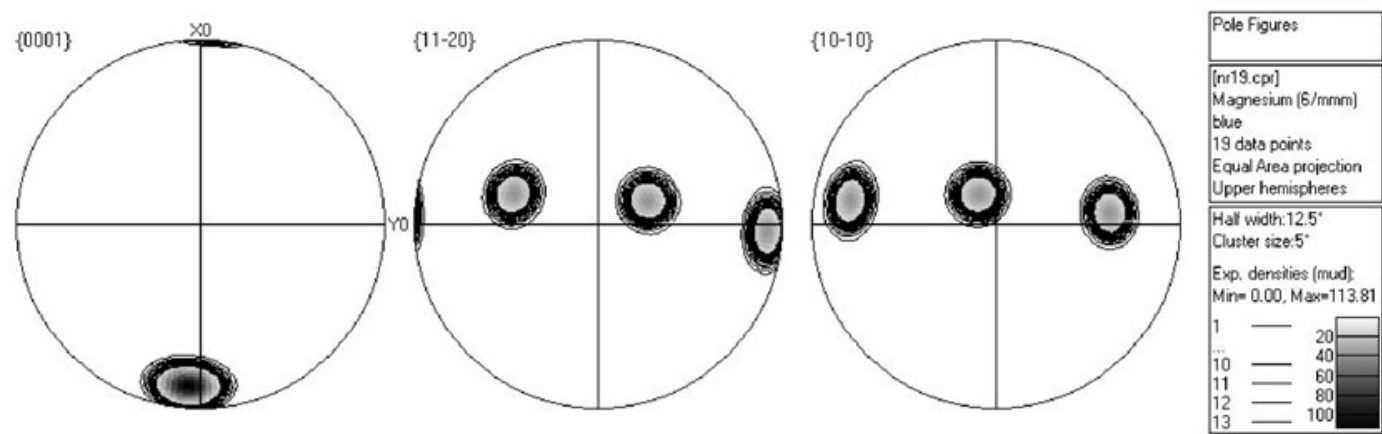

(c)
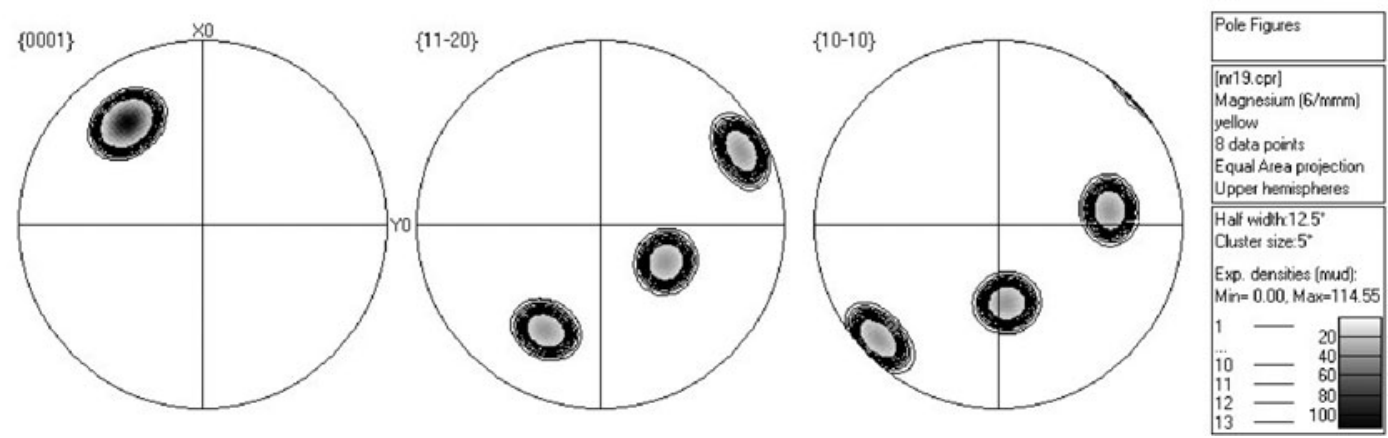

Figure 3. Three pole figures illustrating the matrix and two tensile twin (TTW) variants in Figure 2c: (a) matrix, $\left\{174.4^{\circ}, 127.1^{\circ}, 43.0^{\circ}\right\},(\mathbf{b}) \mathrm{TTW} 1,\left\{95.5^{\circ}, 79.7^{\circ}, 23.8^{\circ}\right\}$, and (c) TTW2, $\left\{54.1^{\circ}, 121.6^{\circ}, 13.4^{\circ}\right\}$.

(a)

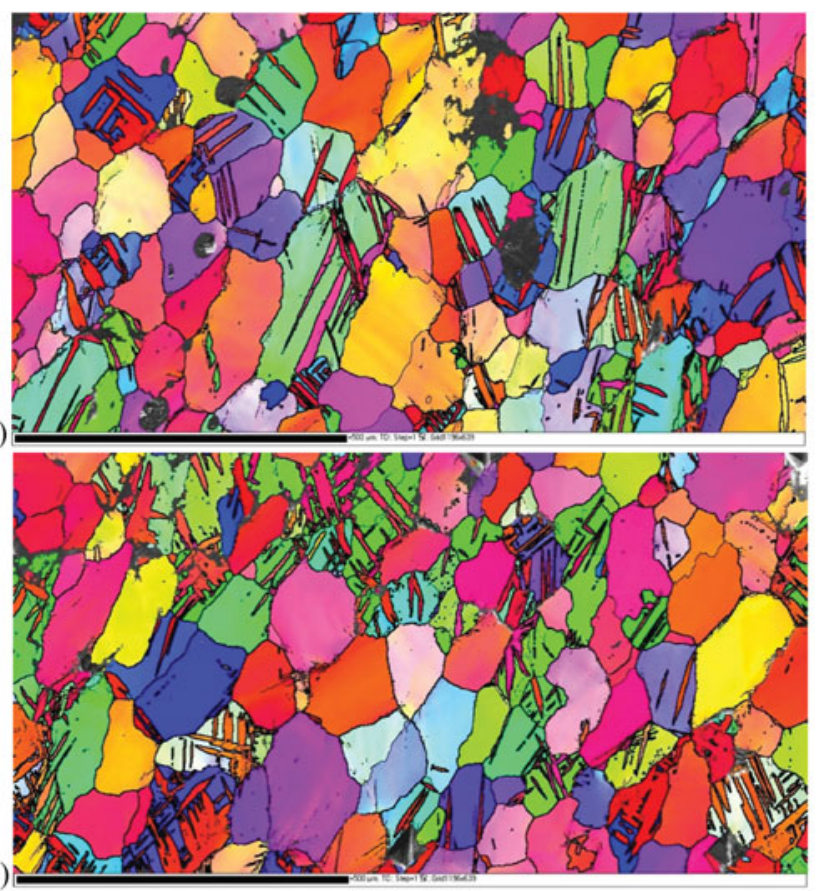

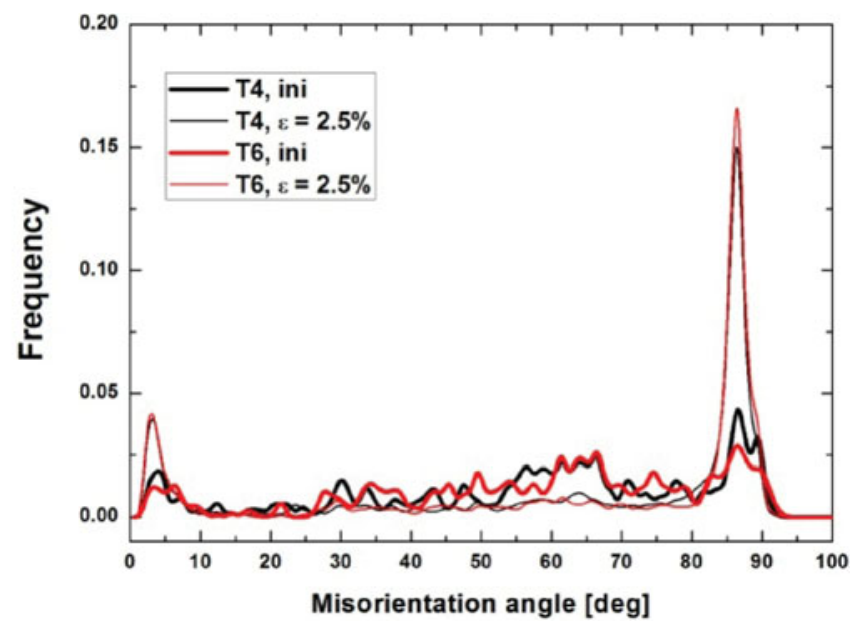

(c)

Figure 4. Electron backscatter diffraction results during uniaxial compression $(\varepsilon=2.5 \%)$ of solid solution and peak-aged ZK60. Thick lines represent a grain identification (GID) angle of $15^{\circ}$, and thin lines, a GID of $2^{\circ}$ : (a) solid solution (T4), (b) peak-aged (T6) samples, and (c) misorientation angle distribution. 
Many precipitates formed by the aging process contributed to an increase in the hardness of ZK60 alloys because of an increase in the interaction between the precipitates and dislocations. In addition, the aging process could change the chemical composition in the matrix, such as that of $\mathrm{Zn}$ and $\mathrm{Zr}$, and the variations in the proportions of the elements could affect the stacking fault energy (SFE) of ZK60 alloys. The kinetics of deformation twinning was also related with the variation in the SFE, and thus some difference in the deformed microstructure and texture between the T4 and T6 samples was expected. The two-dimensional EBSD approach in this case, however, was insufficient to delicately investigate the texture and microstructure variation with the aging heat treatment of ZK60 alloys. Therefore, it is necessary to further investigate the effect of heat treatment on the twinning and slip behaviors through other methods, such as a dislocation analysis (TEM) or a diffraction profile analysis (XRD or Neutron).

\section{CONCLUSIONS}

Texture and microstructure evolution of the wrought magnesium alloys of ZK60 ( $\mathrm{Mg}-\mathrm{Zn}-\mathrm{Zr}$ ) was examined during microindentation and uniaxial compression using EBSD and TEM. ZK60 is a type of precipitate hardening material, and its strength and hardness change with aging. The slip and twinning behaviors near indentation marks were examined. Two twin variants were usually observed near randomly selected indentation marks, and they were TTWs. Twinning and slip behaviors were further examined by uniaxial compression. Some grains with nonbasal orientations aligned with LD underwent twinning followed by slip deformation. Other grains near basal orientations just revealed slip deformation.

\section{ACKNOWLEDGMENTS}

This work was supported by national grants funded by the Ministry of Knowledge Economy and the Korea Institute of Materials Science.

\section{REFERENCES}

Agnew, S.R. \& Duygulu, O. (2005). Plastic anisotropy and the role of non-basal slip in magnesium alloy AZ31B. Int J Plast 21, 1161-1193.

Agnew, S.R., Yoo, M.H. \& Tome, C.N. (2001). Application of texture simulation to understanding mechanical behavior of $\mathrm{Mg}$ and solid solution alloys containing Li and Y. Acta Mater 49, 4277-4289.

Chen, H., Kang, S.B., Yua, H., Cho, J.H., Kim, H.W. \& Mina, G. (2009). Effect of heat treatment on microstructure and mechanical properties of twin roll cast and sequential warm rolled ZK60 alloy sheets. J Alloys Compd 476, 324-328.

Cho, J.H., Jin, Y.M., KIm, H.W. \& KANG, S.B. (2007). Microstructure and mechanical properties of ZK60 alloy sheets during aging. Mater Sci Forum 558-559, 159-164.

Cho, J.H., Rollett, A.D. \& Он, K.H. (2005). Determination of a mean orientation in electron backscatter diffraction measurements. Metall Mater Trans A 36(12), 3427-3438.

Choi, S.H., Shin, E.J. \& SEONG, B.S. (2007). Simulation of deformation twins and deformation texture in an AZ31 Mg alloy under uniaxial compression. Acta Mater 55, 4181-4192.

GAO, X. \& NiE, J.F. (2007). Characterization of strengthening precipitate phases in a Mg-Zn alloy. Scr Mater 56(8), 645-648.

He, S.M., Peng, L.M., Zeng, X.Q., Ding, W.J. \& Zhu, Y.P. (2006). Comparison of the microstructure and mechanical properties of a ZK60 alloy with and without $1.3 \mathrm{wt} . \%$ gadolinium addition. Mater Sci Eng A 433, 175-181.

Lorimer, G. \& Mackenzie, L. (2005). An EBSD study of deformation and recrystallization in magnesium alloys. Microsc Microanal 11(Suppl 2), 192-193.

Maeng, D.Y., Kim, T.S., Lee, J.H., Hong, S.J., Seo, S.K. \& Chun, B.S. (2000). Microstructure and strength of rapidly solidified and extrusion Mg-Zn alloys. Scr Mater 43, 385-389.

Nave, M.D. \& Barnett, M.R. (2004). Microstructures and textures of pure magnesium deformed in plane-strain compression. Scr Mater 51, 881-885.

Wei, L.Y., Dunlop, G.L. \& Westengen, H. (1995a). The intergranular microstructure of cast $\mathrm{Mg}-\mathrm{Zn}$ and $\mathrm{Mg}-\mathrm{Zn}$-rare earth alloys. Metall Trans A 26, 1947-1955.

Wei, L.Y., Dunlop, G.L. \& Westengen, H. (1995b). Precipitation hardening of Mg-Zn and Mg-Zn-RE alloys. Metall Trans A 26, 1705-1716.

Xu, D.K., Liu, L., Xu, Y.B. \& Han, E.H. (2006). The effect of precipitates on the mechanical properties of ZK60-Y alloy. Mater Sci Eng A 420, 322-332. 